\title{
In vitro Differentiation of Human TERT-Transfected Multi-Lineage Progenitor Cells (MLPC) into Immortalized Hepatocyte-Like Cells
}

This article was published in the following Dove Press journal: Hepatic Medicine: Evidence and Research

\author{
Daniel P Collins $\mathbb{D}^{\prime}$ \\ Joel H Hapke' \\ Rajagopal N Aravalli (iD) \\ Clifford J Steer ${ }^{3,4}$ \\ 'Cytomedical Design Group, LLC, Saint \\ Paul, MN 55I27, USA; '2Department of \\ Electrical and Computer Engineering, \\ College of Science and Engineering, \\ University of Minnesota, Minneapolis, \\ MN 55455, USA; ${ }^{3}$ Department of \\ Medicine, University of Minnesota \\ Medical School, Minneapolis, MN 55455, \\ USA; ${ }^{4}$ Department of Genetics, Cell \\ Biology and Development, University of \\ Minnesota Medical School, Minneapolis, \\ MN 55455, USA
}

Correspondence: Daniel P Collins CMDG, LLC, Saint Paul, MN 55I27, USA Email dc@cmdgllc.com
Background: Research directed towards drug development, metabolism, and liver functions often utilize primary hepatocytes $(\mathrm{PH})$ for preliminary in vitro studies. Variability in the in vitro functionality of $\mathrm{PH}$ and the unsuitability of hepatocarcinoma cells for these studies have driven researchers to look to ESC, iPS, and other stem cell types using differentiation protocols to provide more reliable and available cells. This study describes the development of hepatocyte-like cells through the in vitro differentiation of human TERT-immortalized cord blood-derived multi-lineage progenitor cells (MLPC). The E12 clonal cell line derived from polyclonal TERT-transfected cells was used throughout the study.

Methods: E12 MLPC were subjected to a three-step differentiation protocol using alternating combinations of growth factors, cytokines, and maturational factors. Cells at various stages of differentiation were analyzed for consistency with PH by morphology, immunohistochemistry, urea production, and gene expression.

Results: E12 MLPC were shown to significantly change morphology with each stage of differentiation. Coincidental with the morphological changes in the cells, immunohistochemistry data documented the differentiation to committed endoderm by the expression of SOX17 and GATA-4; the progression to committed hepatocyte-like cells by the expression of a large number of markers including $\alpha$-fetoprotein and albumin; and the final differentiation by the expression of nuclear and cytoplasmic HNF4. Fully differentiated cells demonstrated gene expression, urea production, and immunohistochemistry consistent with $\mathrm{PH}$. A methodology and medium formulation to continuously expand the E12-derived hepatocyte-like cells is described.

Conclusion: The availability of immortalized hepatocyte-like cell lines could provide a consistent tool for the study of hepatic diseases, drug discovery, and the development of cellular therapies for liver disorders. Utilization of these techniques could provide a basis for the development of bridge therapies for liver failure patients awaiting transplant.

Keywords: cord blood, TERT, MLPC, differentiation, hepatocyte-like cells

\section{Introduction}

The study of systemic liver metabolism, liver disorders, the development of new therapies, and toxicological studies of drug metabolism are dependent upon the availability of primary human hepatocytes (PHs) for in vitro assays. The current source for primary hepatocytes is from livers deemed unsuitable for transplantation. PHs are limited by (i) variable in vitro viability of the cells; (ii) plate-ability of the cells (do they adhere and spread); (iii) diminishing enzymatic activity during in vitro 
culture over time; (iv) large variability between donor hepatocytes in terms of plate-ability, enzymatic activity, albumin and urea production, and toxicological activity; and (v) limited capacity for in vitro expansion, thus limiting the potential numbers of specific donor cells for these studies. ${ }^{1,2}$ Moreover, a stable repeatable cellular standard for these assays is currently lacking. Immortalized, expandable, stable cell lines with the functional characteristics of normal human hepatocytes could provide a useful and repeatable tool for large-scale studies of hepatocytes.

Previous reports have explored the potential of cord blood-derived MSC differentiation into hepatocyte-like cells. Methodologies included in vivo differentiation, ${ }^{3}$ and various methods of in vitro differentiation using combinations of growth factors and defined chemicals in 1, 2 or 3 step differentiation protocols utilizing growth factors including hepatocyte growth factor, epithelial growth factor, FGF and oncostatin M. ${ }^{4-9}$ Additionally, it was reported that hepatocyte differentiation was achieved utilizing a telomerase stabilized MSC. ${ }^{10}$

This study reports the differentiation protocols and methods of expansion of TERT-immortalized cord bloodderived multi-lineage progenitor cells (MLPC) to create a long-lived cell line with the functional characteristics of mature human hepatocytes. In an effort to produce immortalized MLPC, the un-cloned cells were transfected with the gene for hTERT. Single-cell cloning produced several clonal cell lines capable of extensive expansion. Of those clonal cell lines, $10 \%$ of them retained the differentiation capacity of the non-transfected MLPC. The E12 cell line, exhibiting the greatest differentiation and expansion capacity, were used throughout this study. E12 cells have been in continuous culture for 12 years.

MLPC represent a series of clonal cell lines derived from mesenchymal-like stem cells (MSC) isolated from human umbilical cord blood that are characterized by their extensive expansion capacity, ability to be differentiated to non-mesenchymal outcomes and not form teratomas. ${ }^{11-17}$ MLPC represent approximately 5-10\% of the original MSC isolates and were demonstrated to differentiate into cells representing endo-, meso- and ectodermal origins. ${ }^{18-20}$ Hepatocyte-differentiated E12 cells, developed by the methodology described in this study, have been cultured for almost 2 years and have retained their hepatocyte characteristics. Cells produced by this method could provide the basis for the establishment of a stable, extensively expandable hepatocyte-like cells for hepatocyte functionality studies, drug development, toxicology and the development of methods useful for cellular therapy.

\section{Materials and Methods Isolation of MLPC}

Umbilical cord blood was collected as part of a study to develop PrepaCyte-CB, an FDA-allowed product to debulk cord blood for cryo-banking and transplantation for hematopoietic reconstruction after myeloablation. The cord blood samples were collected by the American Red Cross Cord Blood Program in Saint Paul, Minnesota and Ridgeview Medical Center (Waconia, MN). Donations were collected with informed donor consent for research use only with no identifiers available for the donors. IRB approval of the studies was conducted by the University of Minnesota and the Saint Louis Cord Blood Bank. Collection of human umbilical cord blood was IRB approved by Quorum Review Protocol \#800, March 3, 2005.

MLPC were isolated from human umbilical cord blood by a negative selection sedimentation method using PrepaCyte-MSC (P-MSC, CMDG, LLC, Saint Paul, MN). Cord blood was mixed 50:50 with PrepaCyte for 30 minutes and allowed to sediment for an additional 30 minutes. Suspension cells, comprising lymphocytes, hematopoietic stem cells and mesenchymal stem cells were removed and centrifuged at $400 \mathrm{x}$ g for 7 minutes. Cultures of MSC-like cells were established by plating cells at a concentration of $1.33 \times 10^{6} / \mathrm{cm}^{2}$ in MSCGM medium (PT-4105, Lonza, Walkerville, MD). After 24 hours, non-adherent cells were removed, leaving adherent cells with mostly a fibroblastic morphology. Cells were cultured in MSCGM until 80-90\% of the cells had a fibroblastic morphology. These cells were used to develop MLPC clonal cell lines, TERT-transfected polyclonal cells and clonal TERT cell lines.

\section{hTERT Vector Production}

The telomerase vector was produced by three plasmid transient transductions using $10 \mu \mathrm{g}$ of the self-inactivating pRRL sinhCMV hTERT lentiviral expression plasmid, $10 \mu \mathrm{g}$ of the gag/pol plasmid, pCMV delta 8.2 , and $2 \mu \mathrm{g}$ of the envelope plasmid, pCMV VSVG, according to the manufacturer's directions (Clontech). At 60-70\% confluence HEK $293 \mathrm{~T}$ cells in a $10 \mathrm{~cm}$ dish, fresh medium (DMEM, 10\% FBS without antibiotics) was exchanged 3-4 hours prior to transduction. After overnight incubation (at $37^{\circ} \mathrm{C}, 5 \% \mathrm{CO}_{2}$ ), the medium was replaced and 
incubated for an additional 24 hours. The supernatant was collected and filtered through a $0.45 \mu \mathrm{m}$ filter and stored at $-80^{\circ} \mathrm{C}$. The plasmid vector was kindly provided by Dr. Noriyuki Kashara, Department of Medicine, UCLA, Los Angeles, CA.

\section{Transduction of Normal MLPC}

Twenty-four hours prior to transduction, mixed MLPC cultures were seeded at a density of $5 \times 10^{4}$ cells/well of a 6-well tissue culture dish in complete MSCGM (without antibiotics). Growth medium was removed and replaced with $1 \mathrm{~mL}$ of vector supernatant diluted 1:10 with DMEM $10 \%$ FBS containing $8 \mu \mathrm{g} / \mathrm{mL}$ polybrene. After 4 hours, the vector supernatant was removed and replaced with MSCGM. In parallel, MLPC were also transduced with serially diluted pRRL sinhCMV GFP vector supernatants. FACS analysis was used to estimate GFP expression after 60 hours post transduction. The estimated effective titer of the GFP vector supernatant was $5 \times 10^{4}$. The mixed MLPC transfected cells were kindly provided by Dr. Eve Kelland, Department of Neurology, Keck School of Medicine, USC, Los Angeles, CA.

\section{Development of Clonal Cell Lines}

Polyclonal MLPC were seeded in a 96 well tissue culture plate at a concentration of 30 cells $/ 20 \mathrm{~mL}$ of MSCGM (200 $\mu \mathrm{L}$ per well) and were left to adhere overnight. Wells with 1 cell/well were expanded. Upon reaching 60-80\% confluence, wells were harvested and further expanded. Expanded cultures developed from individual wells were analyzed by FACS for positive expression of surface CD90, CD106, negative surface expression of CD31 and the intracellular expression of TERT. Ten stable cell lines were established, with the E12-TERT clone exhibiting the desired expansion and differentiation capacities. The E12 cell line, in serial culture for over 12 years, was used in this study.

\section{Human Mesenchymal Stem Cells}

Human mesenchymal stem cells (hMSC) were obtained from Lonza (PT-2501) and were expanded in MSCGM for use in comparative flow cytometry and confocal analysis with MLPC.

\section{Competitive Hybridization Analysis}

Relative levels of gene expression by MSC and MLPC were analyzed by competitive hybridization utilizing the PIQOR Stem Cell Microarray system analyzing 942 genes associate with stemness and differentiation to ectodermal, mesodermal or endodermal commitment (Miltenyi Biotec). The analysis was performed as a service by Miltenyi Biotec.

\section{Primary Hepatocytes}

Cryo-preserved primary human hepatocytes (Zenotech, Kansas City, KS) were thawed with OptiThaw (Zenotech) medium and enumerated with OptiCount medium in a standard hemacytometer. Cells, at a concentration of $10^{6}$ cells/mL in OptiPlate medium (Zenotech), were plated in collagen-coated 6 well plates (BD Biosciences) at $1 \mathrm{~mL}$ per well. After 4 hours of plating, the medium was changed to OptiCulture medium (Zenotech) and exchanged every 24 hours.

\section{Flow Cytometry}

Flow cytometric analysis was used to compare cell surface phenotypic antigen expression of MLPC to hMSC. Briefly, $10^{5}$ cells were incubated with $10 \mu \mathrm{L}$ of phycoerythrinlabelled antibodies (all from Becton Dickinson) for $40 \mathrm{~min}$ at room temperature. Unbound antibody was removed by washing with PBS. Analysis was performed on a Coulter EPICS Elite flow cytometer.

\section{Differentiation of MLPC to Hepatocyte-Like Cells}

Initial attempts to replicate the results using previously reported differentiation methodologies ${ }^{4-10}$ were insufficient to achieve well-defined hepatocyte-like cells resulting only in primitive immature hepatocyte-like cells. Thus, it became necessary to develop a three-step differentiation protocol that included a combination of cytokines, growth factors and defined chemicals.

Differentiation of MLPC to hepatocyte-like cells was accomplished by a 3-step culture protocol. 5 x $10^{5} \mathrm{MLPC} /$ $\mathrm{mL}$ in Williams Medium E with 10\% FBS (Gibco, A1217601, St. Louis, MO) in collagen-coated T-75 flasks (13 mL) or collagen-coated 6 well plates $(2 \mathrm{~mL}$ per well). After overnight culture, allowing cellular adherence, the medium was exchanged and replaced with Hepatocyte Basal Medium (Williams Medium E supplemented with 2\% fatty acid-free BSA (Sigma, A7030), 1\% ITS solution (Lonza, 17-838Z), $5 \mathrm{mM}$ hydrocortisone 21-hemisuccinate (Sigma, H2270) and glutamax (35,050, Gibco)) supplemented with $100 \mathrm{ng} / \mathrm{mL}$ Activin A (338-AC, R\&D Systems). Cells were grown in this medium for 5-7 days with one change of medium. 
The second stage of culture was initiated by changing culture medium to Hepatocyte Induction Medium (Hepatocyte Basal Medium supplemented with FGF basic (20 ng/mL) (233-FB), FGF-4 (20 ng/mL) (7460-F4), HFG $(40 \mathrm{ng} / \mathrm{mL}) \quad$ (294-HG), SCF $(40 \mathrm{ng} / \mathrm{mL}) \quad(255-\mathrm{SC})$, Oncostatin M (20 ng/mL) (295-OM), BMP-4 (20 ng/mL) (314-BP), EGF (40 ng/mL) (236-EG) and IL-1 $\beta(20 \mathrm{ng} / \mathrm{mL})$ (201-LB)). Cells are grown in this medium for 2 weeks, with 3 medium changes per week.

The final stage of differentiation was initiated by exchanging Hepatocyte Induction Medium for Hepatocyte Maturation Medium (Hepatocyte Basal Medium supplemented with FGF basic (20 ng/mL), FGF-4 (20 ng/mL), HFG (40 ng/mL), SCF (40 ng/mL), Oncostatin M (20 ng/mL), BMP-4 (20 ng/mL), EGF (40 ng/mL), IL-1 $\beta(20 \mathrm{ng} / \mathrm{mL})$, $0.5 \%$ DMSO (D2650, Sigma) and $30 \mu \mathrm{g} / \mathrm{mL}$ retinoic acid (R2625, Sigma)). Cells were grown for an additional 7 days before harvesting for analysis or cryopreservation. All cytokines and growth factors were obtained from R\&D System (Minneapolis, MN). After final differentiation, hepatocyte-like MLPC were maintained and expanded in Hepatocyte Induction Medium.

\section{Confocal Immunofluorescent Analysis}

Control E12 cells and cells at the various stages of differentiation were harvested by dissociation with Tryp-LE (12,605-028, Life Technologies, Grand Island, NY). The various cell types were resuspended in the appropriate medium for their state of differentiation at a density of $10^{5} \mathrm{cells} / \mathrm{mL}$. Two hundred $\mu \mathrm{L}$ of cell suspension was added to each well of a collagen-coated 16-well glass chamber slide (Nalge, Nunc International, Rochester, NY) and allowed to adhere overnight. To prepare the cells for staining, cells were fixed for 1 hour in $1 \%$ formalin, and permeabilized by PermaCyte Medium (WBP-1000, CMDG, St. Paul, MN). To analyze the expression of hepatocyte-associated markers: alkaline phosphatase (MAB1448), $\alpha$-fetoprotein (MAB1369), albumin (MAB1456), c-reactive protein (MAB17071), hepatocyte growth factor receptor (MAB3583), nestin (MAB1269), SOX-17 (MAB1924), asialoglycoprotein receptor 1 (MAB4394), hepatocyte nuclear factor-4 (ABIN561308), GATA-4 (MAB2606), $\alpha$-1-antitrypsin (MAB1268), cytokeratin19 (MAB3608), SOX-2 (AF2018), SOX-9 (AF2018), EpCAM (MAB9601), Oct 3/4 (MAB1759) 100 ng of monoclonal antibodies obtained from R\&D Systems (Minneapolis, MN), coagulation factor VII (MA5-16,932), coagulation factor IX (HYB133-01-02) (from Invitrogen, Rockford, IL), P450 CYP 1A2 (ab151728), P450 CYP 3A4 (ab124921), glucuronosyltransferase isoforms UGT1A1 and UGT2B7 (ab126269 and ab194697 from Abcam, Cambridge, MA), and TERT (NB100-317 from Novus, Littleton, CO) were used to label cells for 40 minutes. Unbound antibody was removed by washing with PermaCyte and the cells were counterstained with secondary antibodies specific for mouse (A-11,005), rabbit $(\mathrm{A}-11,072)$, rat $(\mathrm{A}-11,007)$ or goat (A-11,080) antibody labelled with Alexa 594 dye (Life Technologies (Eugene, OR)). The nucleus of the cells was visualized by staining with DAPI. Marker expression was confirmed by positive staining when compared to cells stained with antibody isotype controls (QTC1000, CMDG, St. Paul, MN) analyzed using the Olympus Fluoview 1000 confocal microscope.

\section{Urea Production}

Urea synthesis was determined with a colorimetric assay (K376-100, Biovision, Milpitas, CA). Cells at each stage of differentiation were cultured for 3 days in the medium specific for each cell type. Cells were harvested using the Tryp-LE reagent, counted with a hemocytometer and centrifuged at 400 $\mathrm{xg}$ for 5 minutes to pellet them. Supernatant was discarded and cells were re-suspended in $1 \mathrm{~mL}$ of WIF water (Millipore/ Sigma). Cell membranes were ruptured by three repeated freeze-thaw cycles of freezing at $-80^{\circ} \mathrm{C}$ and thawing at room temperature to release contents into the fluid phase. Lysates were centrifuged at $1000 \mathrm{x}$ g for 10 minutes to pellet cell debris. Lysate supernatant was analyzed by the urea assay, according to the manufacturer's instructions (Biovision). Results were standardized to $1 \times 10^{6}$ cells $/ \mathrm{mL}$ of supernatant. Samples were analyzed on the Emax microplate reader (Molecular Devices. San Jose, CA) and processed with SoftMax PRO 4.8 Analysis Software. E12 MLPC were used as negative controls and PH were used as positive controls. At least three separate determinations were used in the analysis.

\section{PCR Analysis}

Expression of hepatocyte-specific genes was analyzed by PCR. Total RNA was extracted from cells using UltraPure $^{\mathrm{TM}}$ Phenol:Chloroform:Isoamyl Alcohol reagent (Invitrogen). Platinum ${ }^{\circledR}$ Quantitative RT-PCR ThermoScript тм One-Step System (Invitrogen) was used to carry out quantitative RT-PCR reactions according to manufacturer's recommendations. E12 MLPC was used as the negative control, and PH was used as a positive control. Primers are described for $\alpha$-fetoprotein (AFP), $\alpha$-1-antitrypsin (AAT), transthyretin (TTR), cytochrome P450 1A2 (CYP 1A2), cytochrome P450 3A4 (CYP 3A4), cytochrome P450 2C9 
(CYP 2C9), hepatocyte nuclear factor $1 \alpha$ (HNF1A), hepatocyte growth factor (HGF), albumin (ALB), and housekeeping gene glyceraldehyde-3-phosphate dehydrogenase (GAPDH). ${ }^{20-25}$ Primer sequences are shown in Supplemental Table 1. PCR reactions were initiated by denaturation at $94^{\circ} \mathrm{C}$ for $3 \mathrm{~min}$ followed by 30 cycles of denaturation at $94^{\circ} \mathrm{C}$ for $1 \mathrm{~min}$. Annealing was mediated by incubation for $1 \mathrm{~min}$ at $56^{\circ} \mathrm{C}$, and elongation by incubation for $1 \mathrm{~min}$ at $72^{\circ} \mathrm{C}$. PCR products were resolved on a $1 \%$ agarose gel, and visualized under UV light.

\section{Results}

\section{TERT Transfection and Establishment of Cell Lines}

Polyclonal populations of mesenchymal-like cells were isolated from human umbilical cord blood within 48 hours of birth and processed by the methodologies described in the Methods and Materials section. Upon establishment of homogeneous populations of cells and creation of a master cell bank of 3 $\mathrm{x} 10^{7}$ cells, a portion of the cells were transfected with the gene for telomerase reverse transcriptase (TERT). Stable cell cultures of polyclonal cells were developed and cloned by single cell dilution and expansion. A total of 10 cell lines were established that were capable of long-term expansion, but only one cell line expressed the capacity to differentiate beyond the common mesenchymal outcomes of adipocytes, osteoblasts and chondrocytes, the E12 clone. These cells were used throughout the rest of the study. The E12 cell line has been propagated for over 12 years without losing their expression of the TERT gene nor their differentiation capacity.

\section{Phenotypic Comparison of MSC and MLPC}

MSC and MLPC were compared for expression of surface antigens by flow cytometry (Supplemental Table 2) and internal stem cell-associated antigens by confocal microscopy (Supplemental Figure 1). MSC and MLPC were both positive for MSC-associated markers CD9, CD90, CD44, CD73 and CD105. MSC and MLPC were negative for CD45, CD34, CD14, CD3, CD19, CD31, CD36 and CD271. Similarly, MSC and MLPC were negative for class 2 histocompatibility marker HLA-DR and positive for class 1 histocompatibility antigen HLA-ABC. Notably, CD106 was positive in MLPC and negative in MSC. Confocal analysis of stem-cell-associated markers SOX-2 and Oct 3/4 showed distinctive differences between the MSC and MLPC. MSC were negative for both SOX-2 and Oct 3/4, while MLPC were positive for both.

\section{Competitive Hybridization Analysis}

MSC and MLPC were analyzed by competitive hybridization analysis to determine relative expression of 942 genes associated with stemness or level of commitment to ectodermal, mesodermal or endodermal outcomes. In comparison to MSC, 152 genes were up-regulated in MLPC. In particular, the following genes were up-regulated in MLPC: ITGB2, ARHGAP9, CXCR4, INTEGRINB7, PECAM1, PRKCB_1,

\section{E12 Control}
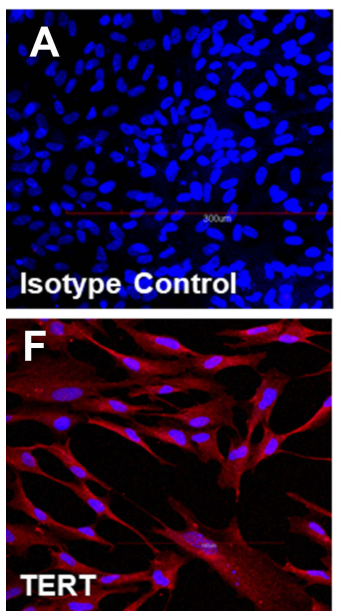

Committed Endoderm
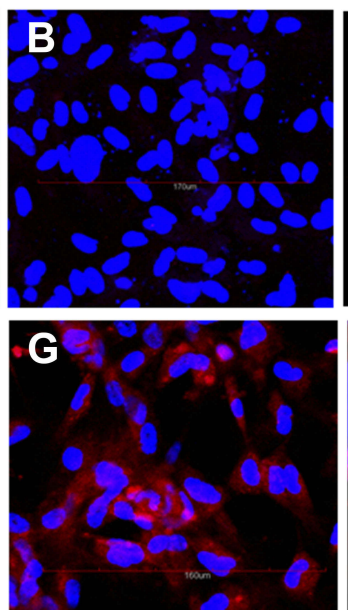

Hepatocyte Precursor
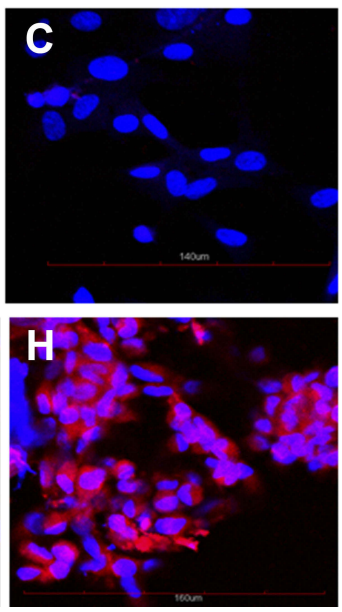

Mature HLC
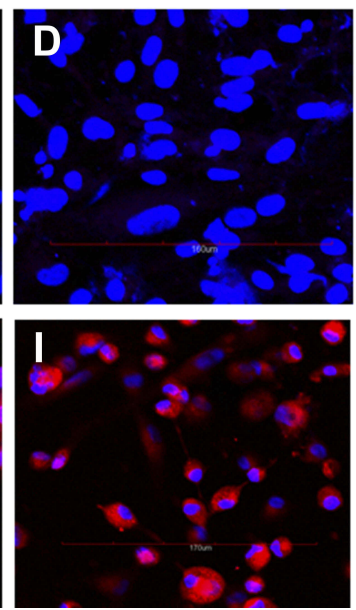

$\mathrm{PH}$

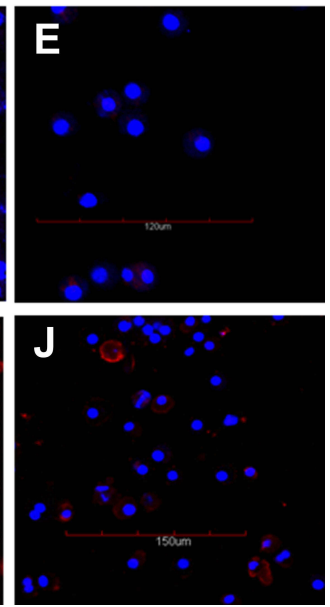

Figure I (A-E) Cells stained with isotype control antibody; and (F-J) TERT-specific antibody. All cells were counterstained with DAPI to visualize nuclei (blue). Cells positive for TERT stained red. (A, F) Undifferentiated control EI2 MLPC; (B, G) EI2 MLPC cultured in Activin A medium (Committed endoderm); (C, H) EI2 cells cultured in Activin A medium and then hepatocyte induction medium (Hepatocyte precursor); (D, I) EI 2 cells cultured in Activin A, hepatocyte induction medium and then hepatocyte maturation medium (Mature HLC); and (E, J) primary human hepatocytes (PH). 
PRKCB 3, IL7R, AIF1,CD45_EX10-11, PLCG2, CD37, PRKCB 2, TCF2_1, RNF138, EAAT4, EPHA1, RPLP0, PTTG, SERPINA1_2, ITGAX, CD24, F11R, RPL4, ICAM1, LMO2, HMGB2, CD38, BMP3, PTHR2, S100B, OSF, SNCA, GRIK1, HTR4, CHRM1, CDKN2D, HNRPA1, IL6R, MUSLAMR, ICAM2, CSK, ITGA6, MMP9, DNMT1, PAK1, IKKB, TFRC_MIDDLE, CHI3L2, IGTA4, FGF20, NBR2, TNFRSF1B, CEBPA_3, CDO1, NFKB1, GATA2,
PDGFRB， ICSBP1，KCNE3，TNNC1，IGTA2B， CCT8, LEFTA, TH, RPS24, HTR1F, TREM1, CCNB2, SELL, CD34, HMGIY, COX7A2, SELE, TNNT2, SEM2, CHEK1, CLCN5, F5, PRKCQ, ITGAL, NCAM2, ZNF257MGC12518-ZNF92-ZNF43-ZNF273-FLJ90430, CDK1, RPL6, RPL24, IGHA1-IGHA2_M, PUM2, GJA7, HTR7, PTHR1, MAPK14, MSI2_1, KCNJ3, CD133, SYP, TFRC_5PRIME, TDGF1-TDGF3_2, FLT3, HPRT,

E12 Control Committed Endoderm Hepatocyte Precursor Mature HLC

$\mathrm{PH}$
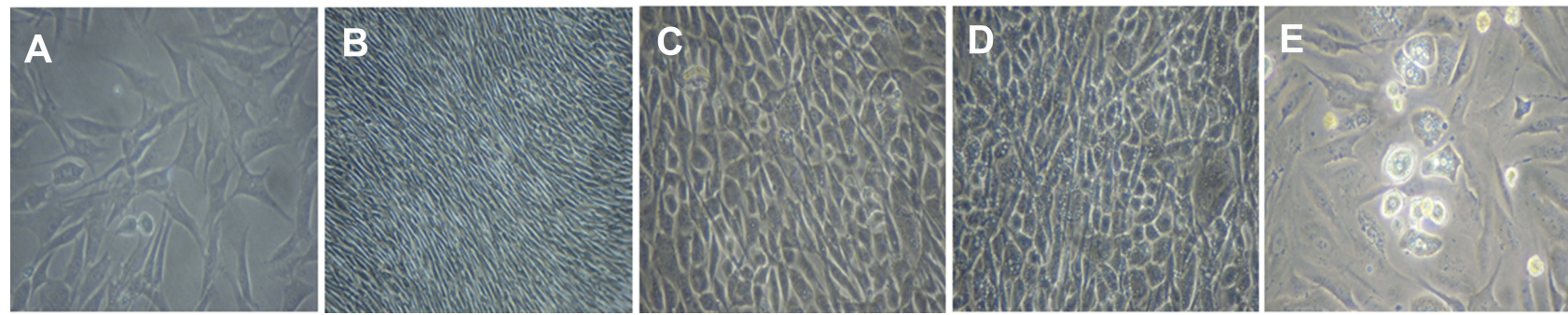

Figure 2 Phase contrast of differentiating MLPC EI2 clone and primary hepatocytes. (A) EI 2 clone of MLPC-TERT cells; (B) MLPC EI2 clone after 6 days of differentiation in Activin A medium (Committed endoderm); (C) MLPC EI2 clone differentiated for 6 days in Activin A medium and 14 days of differentiation in hepatocyte induction medium (Hepatocyte precursor); (D) MLPC EI2 clone differentiated for 6 days in Activin A medium, followed by differentiation for 14 days in hepatocyte induction medium and 7 days of differentiation in hepatocyte maturation medium (Mature HLC); and (E) primary human hepatocytes (PH).

E12 Control
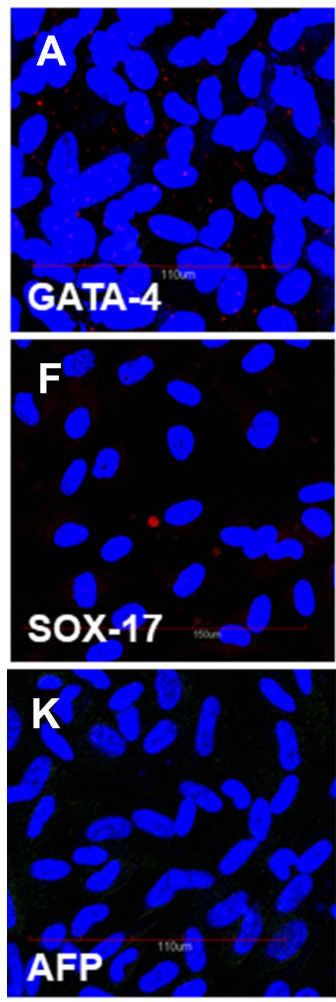

Committed Endoderm Hepatocyte Precursor

\section{Mature HLC}
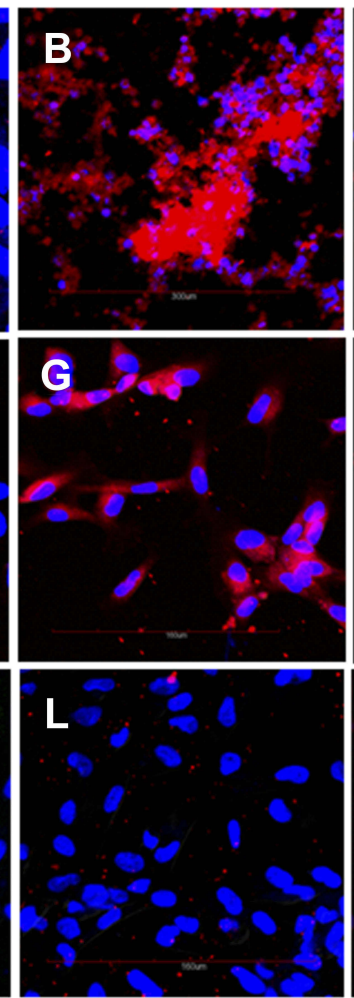
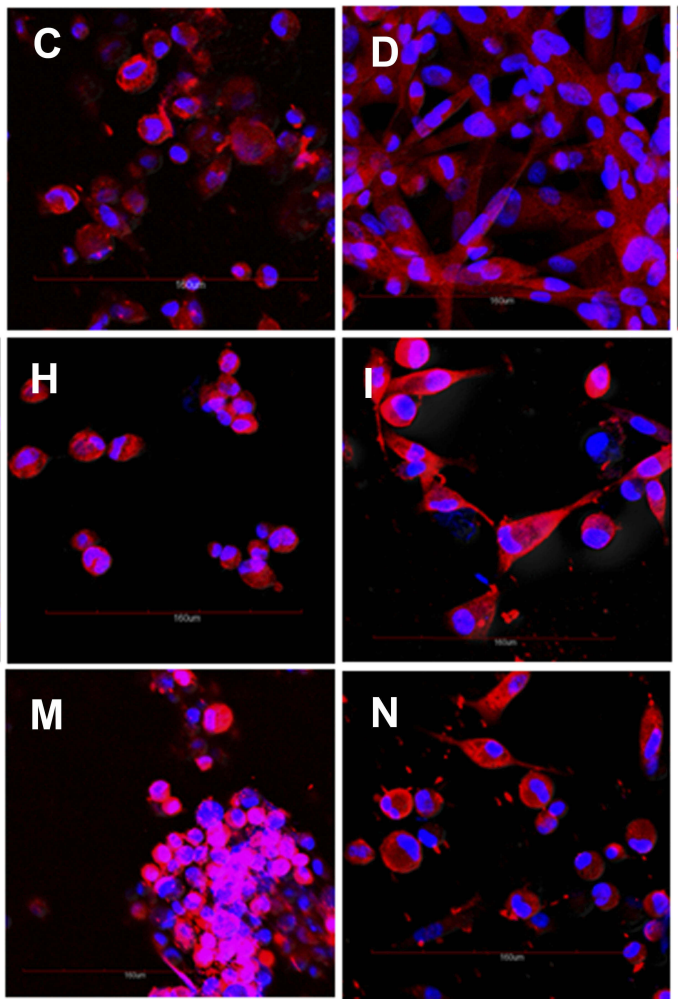

PH

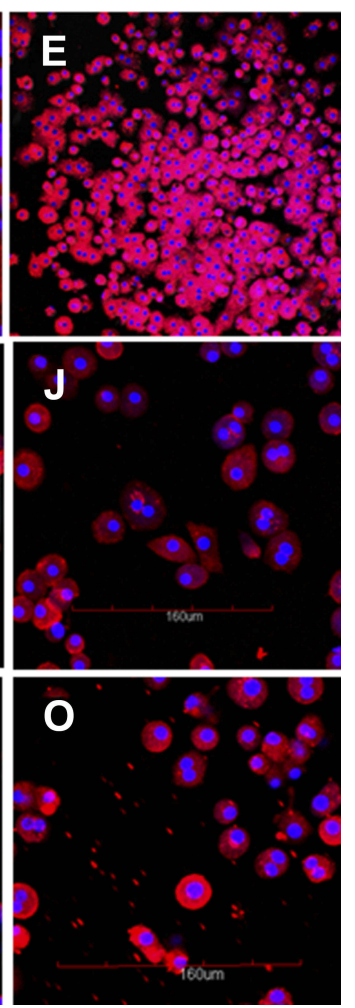

Figure 3 Cells stained with (A-E) anti-GATA-4 antibody; (F-J) SOX-I7 specific antibody and (K-O) alpha fetoprotein-specific antibody. All cells were counterstained with DAPI to visualize nuclei (blue). Cells positive for GATA-4, SOX-I7 and alpha fetoprotein stained red. (A, F, K) Undifferentiated control EI2 MLPC; (B, G, L) EI2 MLPC cultured in Activin A medium (Committed endoderm); (C, H, M) EI 2 cells cultured in Activin A medium and then hepatocyte induction medium (Hepatocyte precursor); (D, I, N) EI 2 cells cultured in Activin A, hepatocyte induction medium and then hepatocyte maturation medium (Mature HLC); and (E, J, $\mathbf{O})$ primary human hepatocytes (PH). 
SEMA4D, ITGAM, KIAA0152_3, ZFP42, SOX20, FLJ21190, CPN2, POU2F2, CASP8_1, CLDN10, TREM2, TERT, OLIG1, EGR2, CD44_EX3-5, CD33, CNTFR, OPN, COL9A1_2, ROBO4, HTR1D_1, IKKA, KIT, NPPA, PRKCH, FGF4, CD68, NUMB, NRG3, SALL2, NOP5, HNF4G, FIBROMODULIN, CD58, CALB1, GJB5, GJA5, POU5F_1, GDF5, POU6F1, CD44_EX16-20, BCAN, PTEN1-PTEN2, AGRIN, ALB, KCNQ4, DPPA5, EPHB2, TGFBR2 and ITGA3. The immaturity of MLPC in comparison to MSC was characterized by the overexpression of CXCR4, FLT3, TERT, KIT, POU5F and the CD markers CD9, CD34 and CD133.

\section{Expression of TERT}

The E12 clone was developed from a polyclonal population of cells that were not exclusively MLPC nor were they exclusively TERT + . The cells that developed out of the transfection and cloning were selected by growth characteristics initially and then by differentiation capacity, the E12 clone being the most favorable clone that satisfied all the desired characteristics. The expression of the TERT gene in the initial undifferentiated E12 cell line and their differentiated progeny were analyzed by immunohistochemistry. As shown in Figure 1, MLPC E12 cells expressed the TERT gene when analyzed by immunohistochemistry and in their subsequent differentiated states. Interestingly, primary hepatocytes expressed low levels of TERT in some cells; earlier studies with non-TERT transfected MLPC showed TERT expression was expressed in MLPC only during the different stages of mitosis, and non-dividing cells were negative.

\section{Differentiation of MLPC to Hepatocyte-Like Cells}

The differentiation of MLPC to hepatocyte-like cells required 3 distinct steps; the first was differentiation to committed

Table I Expression profile of endodermal and hepatocyte-specific markers in MLPC and mature HLC by immunohistochemistry and confocal analysis

\begin{tabular}{|c|c|c|c|c|c|}
\hline Analyte & EI2 MLPC & $\begin{array}{l}\text { Committed } \\
\text { Endoderm }\end{array}$ & $\begin{array}{l}\text { Hepatocyte } \\
\text { Precursor }\end{array}$ & Mature HLC & PH \\
\hline $\begin{array}{l}\text { Alkaline Phosphatase } \\
\text { Alpha Fetoprotein } \\
\text { Albumin } \\
\text { C-reactive Protein } \\
\text { Hepatocyte Growth } \\
\text { Factor Receptor } \\
\text { Coagulation Factor VII } \\
\text { Coagulation Factor IX } \\
\text { Nestin } \\
\text { SOX I7 } \\
\text { P450 CYP 3A4 } \\
\text { P450 CYP IA2 } \\
\text { Asialoglycoprotein } \\
\text { Receptor I }\end{array}$ & $\begin{array}{l}\mathrm{Neg} \\
\mathrm{Neg} \\
\mathrm{Neg} \\
\mathrm{Neg} \\
\mathrm{Neg} \\
\mathrm{Neg} \\
\mathrm{Neg}\end{array}$ & $\begin{array}{l}\text { Neg } \\
\text { Neg } \\
\text { Neg } \\
\text { Pos } \\
\text { Neg } \\
\text { Neg } \\
\text { Neg }\end{array}$ & $\begin{array}{l}\text { Pos } \\
\text { Pos } \\
\text { Pos } \\
\text { Pos } \\
\text { Pos } \\
\text { Neg } \\
\text { Neg } \\
\text { Pos } \\
\text { Pos } \\
\text { Pos } \\
\text { Pos } \\
\text { Pos }\end{array}$ & $\begin{array}{l}\text { Pos } \\
\text { Pos } \\
\text { Pos } \\
\text { Pos } \\
\text { Pos } \\
\text { Pos } \\
\text { Pos } \\
\text { Pos } \\
\text { Pos } \\
\text { Pos } \\
\text { Pos } \\
\text { Pos }\end{array}$ & $\begin{array}{l}\text { Pos } \\
\text { Pos } \\
\text { Pos } \\
\text { Pos } \\
\text { Pos } \\
\text { Pos } \\
\text { Pos } \\
\text { Pos } \\
\text { Pos } \\
\text { Pos } \\
\text { Pos } \\
\text { Pos }\end{array}$ \\
\hline $\begin{array}{l}\text { Hepatocyte Nuclear } \\
\text { Factor } 4 \\
\text { GATA-4 } \\
\text { Alpha-I-Antitrypsin } \\
\text { SOX2 } \\
\text { SOX9 } \\
\text { CK19 } \\
\text { EPCAM } \\
\text { UGTIAI } \\
\text { UGT2B7 }\end{array}$ & $\begin{array}{l}\text { Neg } \\
\text { Neg } \\
\text { Neg } \\
\text { Pos } \\
\text { Pos } \\
\text { Pos } \\
\text { Pos } \\
\text { Neg } \\
\text { Neg }\end{array}$ & $\begin{array}{l}\text { Neg } \\
\text { Pos } \\
\text { Neg } \\
\text { Pos } \\
\text { Pos } \\
\text { Pos } \\
\text { Weak Pos } \\
\text { Neg } \\
\text { Neg }\end{array}$ & $\begin{array}{l}\text { Cytoplasmic Positive, } \\
\text { Nuclear Negative } \\
\text { Pos } \\
\text { Pos } \\
\text { Pos } \\
\text { Pos } \\
\text { Pos } \\
\text { Pos } \\
\text { Pos } \\
\text { Pos }\end{array}$ & $\begin{array}{l}\text { Cytoplasmic Positive, } \\
\text { Nuclear Positive } \\
\text { Pos } \\
\text { Pos } \\
\text { Pos } \\
\text { Pos } \\
\text { Pos } \\
\text { Pos } \\
\text { Pos } \\
\text { Pos }\end{array}$ & $\begin{array}{l}\text { Cytoplasmic Positive, } \\
\text { Nuclear Positive } \\
\text { Pos } \\
\text { Pos } \\
\text { Pos } \\
\text { Pos } \\
\text { Pos } \\
\text { Pos } \\
\text { Pos } \\
\text { Pos }\end{array}$ \\
\hline
\end{tabular}

Notes: Summary of confocal analysis. Undifferentiated MLPC EI 2 clone (left column) was compared to MLPC EI 2 cells cultured for 6 days in Activin A Medium (2nd column), MLPC EI 2 cells cultured for 6 days in Activin A Medium and 2 weeks in Hepatocyte Induction Medium (3rd column), MLPC EI 2 cells cultured for 6 days in Activin A Medium and 2 weeks in Hepatocyte Induction Medium and 7 days in Hepatocyte Maturation Medium (4th column), and normal Primary Human Hepatocytes (right column). 
endodermal cells in the presence of Activin A, the second was the commitment to dedicated hepatocyte precursor cells in the presence of Hepatocyte Induction Medium, the final step was maturation to the final phenotype with the inclusion of DMSO and retinoic acid to the Induction Medium (Hepatocyte Maturation Medium). Each stage of differentiation was characterized by differing morphology (Figure 2) and expression of endodermal- or hepatocytes-specific markers (Figures 3-7) (Table 1). Morphologically, the MLPC had a significant change in their morphology throughout the differentiation process. Initially, MLPC have a largely fibroblastic morphology. After Activin A activation, cells became tightly packed monolayers of spindle-shaped cells. Upon differentiation to the hepatocyte-committed stage, confluent cultures assumed a more cobblestone appearance. After the final maturation culture MLPC maintained their cobblestone appearance with the addition of cytoplasmic vacuoles and liposomes.

By immunohistochemistry, the differentiation of MLPC to committed endodermal cells was characterized by the expression of GATA4 (Figure 3B) and SOX17 (Figure 3G) and lack of expression of the more hepatocytes-specific markers. These included AFP (Figure 3L), albumin (Figure 4B) ASGr1 (Figure 4G), HNF4 (Figure 4L), HGFr (Figure 5B), A1AT (Figure 5G), CYP1A2 (Figure 6B), CYP 3A4 (Figure 6G), UGT1A1 (Figure 7G) and UGT2B7 (Figure 7L). Interestingly, SOX9 (Figure 5K-O), CK19 (Figure 6K-O) and EpCAM (Figure 7A-E) were expressed in undifferentiated MLPC and were maintained throughout the differentiation process. Further differentiation of the MLPC to the committed hepatocyte precursor cell was characterized by the expression of more hepatocyte-specific markers such as $\alpha$-fetoprotein (Figure 3M), albumin (Figure 4C), ASGr1 (Figure 4H), HNF4 (Figure 4M), HGFr (Figure 5C), A1AT (Figure 5H), CYP 1A2 (Figure 6C), CYP 3A4 (Figure 6H), UGT1A1 (Figure 7H) and UGT2B7 (Figure 7M). Notably, HNF4 was expressed only cytoplasmically in the committed hepatocyte precursor cells (Figure 4M), but was also detected within the nucleus of fully mature hepatocyte-like cells (Figure 4N). Not surprisingly, HNF4 was also identified in the nucleus of $\mathrm{PH}$ (Figure 4O). All markers expressed by $\mathrm{PH}$ (Figure 3E, $\mathrm{J}$ and $\mathrm{O}$; Figure 4E, J and O; Figure 5E, J and O; Figure 6E, $\mathrm{J}$ and $\mathrm{O}$; Figure $7 \mathrm{E}, \mathrm{J}$ and $\mathrm{O}$ ) were also expressed by the fully
E12 Control

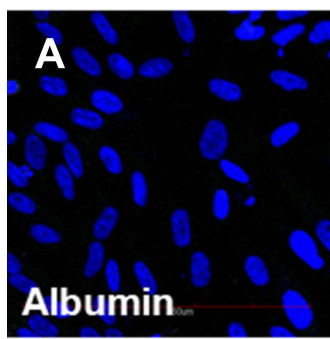

Committed Endoderm
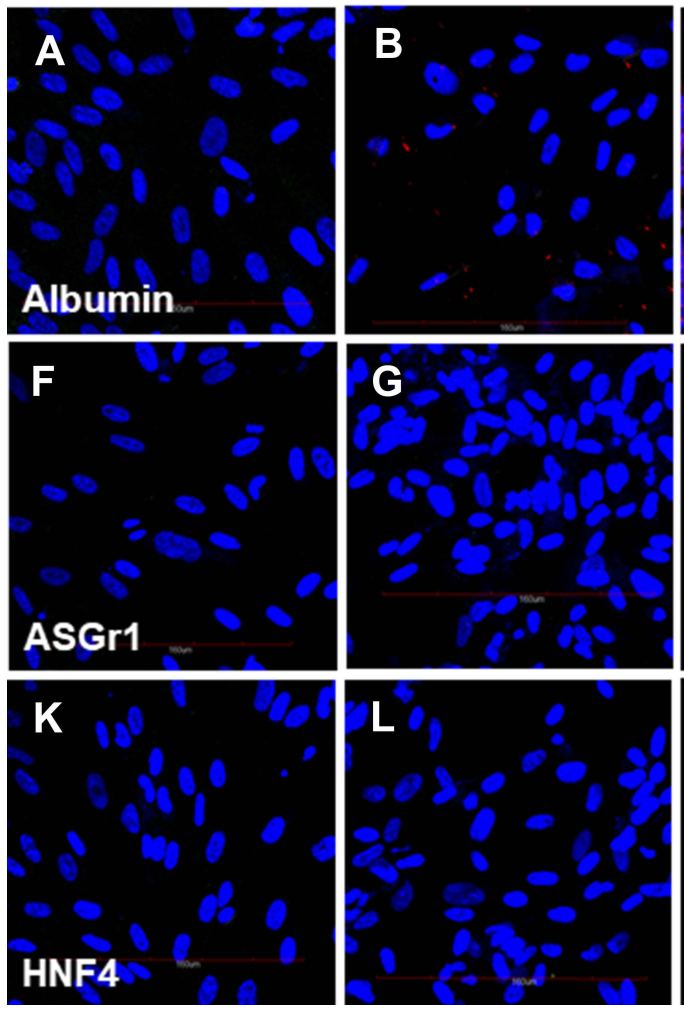

Hepatocyte Precursor

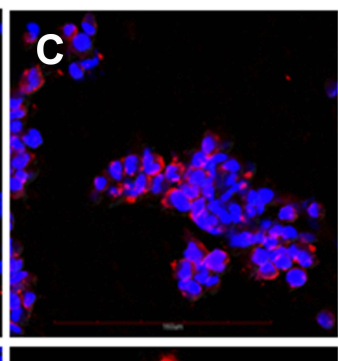

Mature HLC
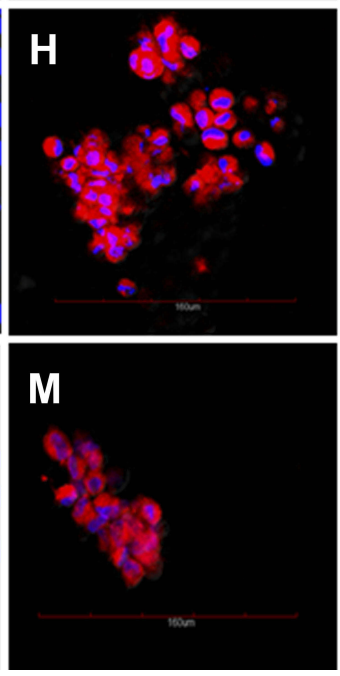
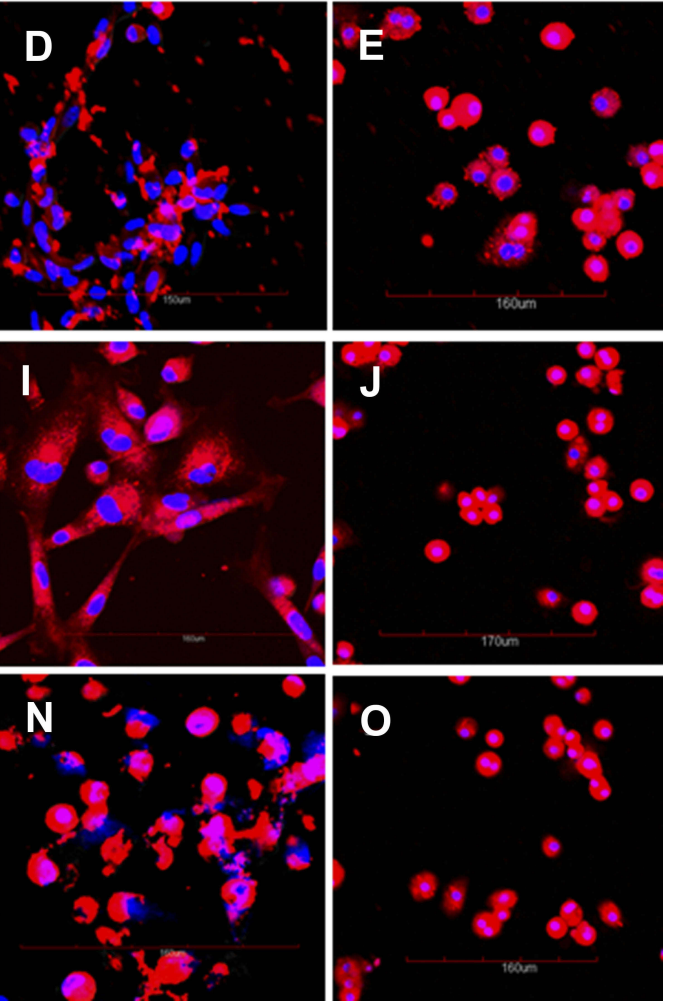

Figure 4 Cells stained with (A-E) albumin-specific antibody; (F-J) ASGr I-specific antibody and (K-O) HNF4-specific antibody. All cells were counterstained with DAPI to visualize nuclei (blue). Cells positive for albumin, ASGrl and HNF4 stained red. (A, F, K) Undifferentiated control EI2 MLPC; (B, G, L) EI2 MLPC cultured in Activin A medium (Committed endoderm); (C, H, M) EI2 cells cultured in Activin A medium and then hepatocyte induction medium (Hepatocyte Precursor); (D, I, N) EI 2 cells cultured in Activin A, hepatocyte induction medium and then hepatocyte maturation medium (Mature HLC); and (E, J, $\mathbf{O})$ primary human hepatocytes (PH). 


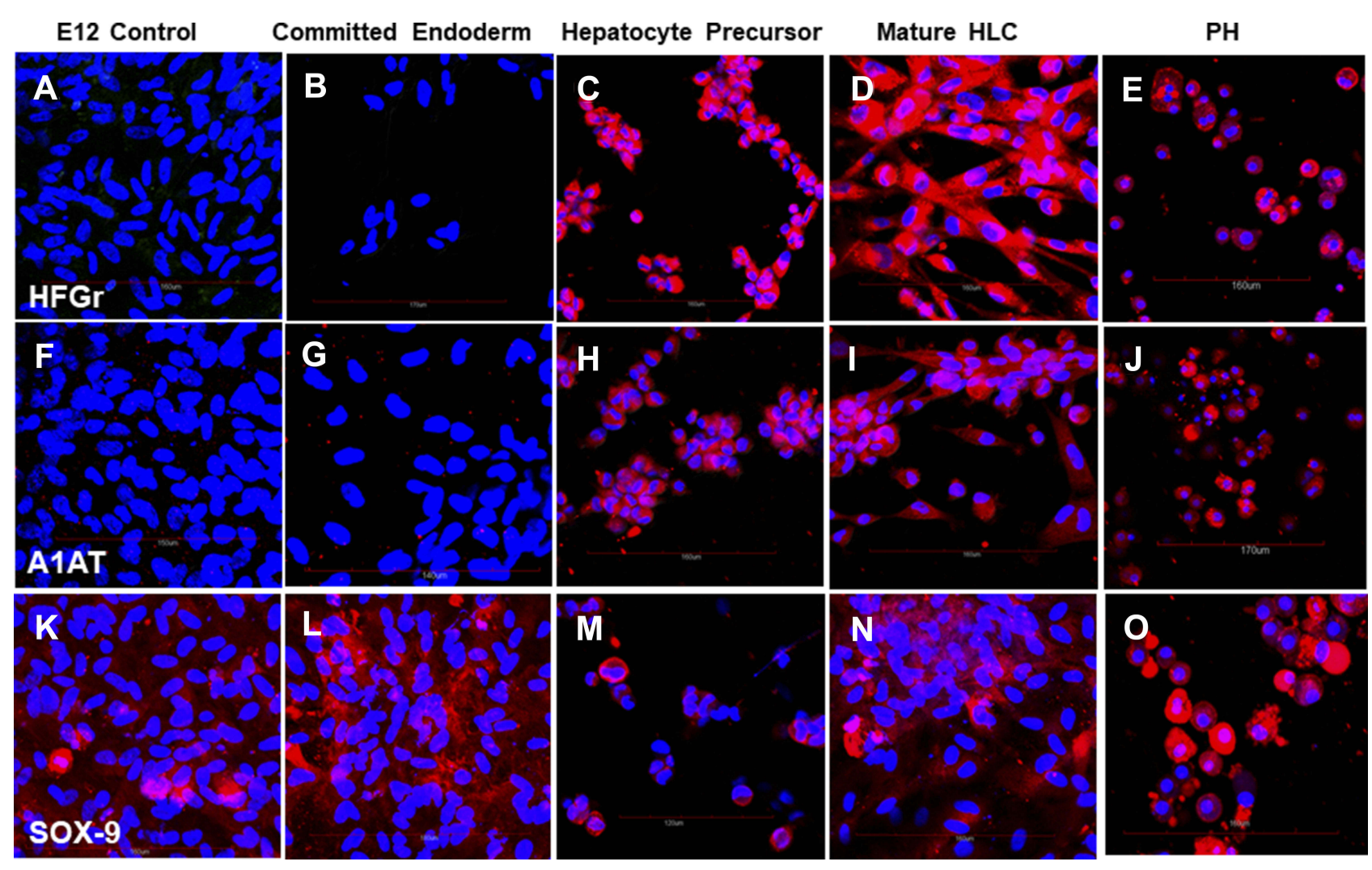

Figure 5 Cells stained with (A-E) HGFr-specific antibody; (F-J) AIAT-specific antibody and (K-O) SOX-9-specific antibody. All cells were counterstained with DAPI to visualize nuclei (blue). Cells positive for albumin, HGFr, AIAT and SOX-9 stained red. (A, F, K) Undifferentiated control EI 2 MLPC; (B, G, L) EI 2 MLPC cultured in Activin A medium (Committed endoderm); (C, H, M) EI2 cells cultured in Activin A medium and then hepatocyte induction medium (Hepatocyte Precursor); (D, I, N) EI2 cells cultured in Activin A, hepatocyte induction medium and then hepatocyte maturation medium (Mature HLC); and (E, J, $\mathbf{O})$ primary human hepatocytes (PH).

mature hepatocyte-like cells (Figure 3D, I and N; Figure 4D, I and N; Figure 5D, I and N; Figure 6D, I and N, Figure 7D, I and N).

\section{Urea Production}

Production of urea is a critical metabolic function of hepatocytes. E12 MLPCs produced very low levels of urea when compared to primary hepatocytes $(1.55 \pm 0.4$ versus $8.28 \pm 2.73$ ). After final differentiation of E12 cells in Hepatocyte Maturation Medium, comparable levels of urea were produced compared to primary hepatocytes (11.09 \pm 0.96 versus $8.28 \pm 2.73$ ).

\section{PCR Analysis}

RNA isolates from E12 MLPC, E12 hepatocyte-like cells and $\mathrm{PH}$ were analyzed for the expression of $\alpha$-fetoprotein (AFP), $\alpha$-1-antitrypsin (AAT), transthyretin (TTR), cytochrome P450 1A2 (CYP 1A2), cytochrome P450 3A4 (CYP 3A4), cytochrome P450 2C9 (CYP 2C9), hepatocyte nuclear factor $1 \alpha$ (HNF1A), hepatocyte growth factor (HGF), albumin (ALB), and housekeeping gene glyceraldehyde-3-phosphate dehydrogenase (GAPDH) by PCR. As shown in Figure 8, E12 MLPC were negative for the hepatocyte-specific markers, while both primary hepatocytes and differentiated E12 MLPC cells expressed similar levels of the hepatocyte-specific markers.

\section{Discussion}

Currently, the treatment for terminal liver disease is a liver transplant. This therapeutic treatment is limited by the availability of transplantable livers. Development of future drug-based therapies is dependent upon the availability of PHs to study potential therapies in vitro prior to testing in animal models and then in human clinical trials. Additionally, the effects of drugs developed for the treatment of other non-liver diseases are tested for their effects on liver function initially by in vitro toxicology testing on PHs. A potential bridge to transplantation for liver failure could also involve the availability of functional hepatocytes or hepatocyte-like cells incorporated into an extra-corporeal device containing those cells. ${ }^{26,27}$ Both of these needs are 


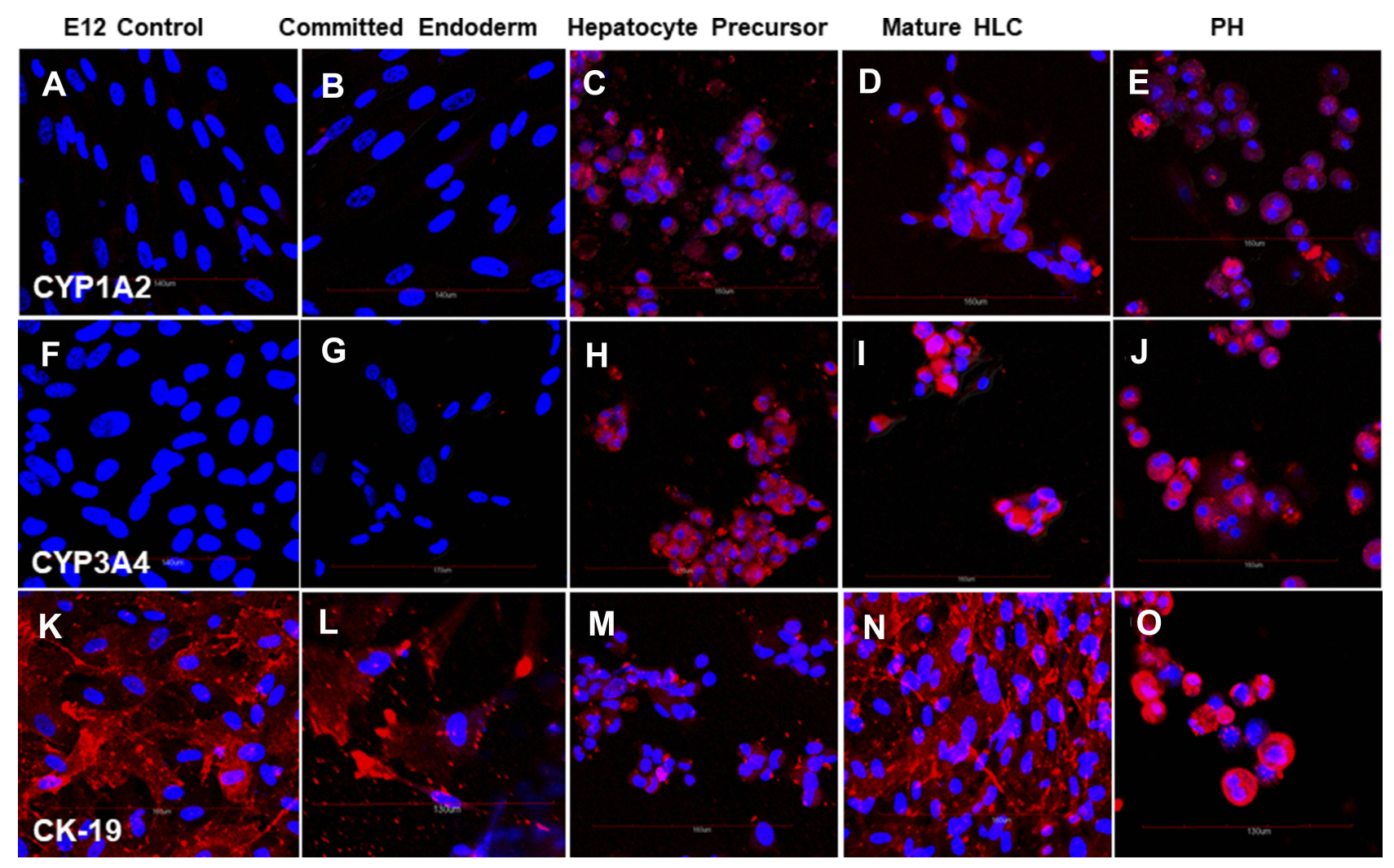

Figure 6 Cells stained with (A-E) P450 CYPIA2-specific antibody; (F-J) P450 CYP3A4-specific antibody and (K-O) CKI9-specific antibody. All cells were counterstained with DAPI to visualize nuclei (blue). Cells positive for P450 CYPIA2, P450 CYP3A4 and CKI9 stained red. (A, F, K) Undifferentiated control EI2 MLPC; (B, G, L) EI2 MLPC cultured in Activin A medium (Committed endoderm); (C, H, M) El2 cells cultured in Activin A medium and then hepatocyte induction medium (Hepatocyte precursor); (D, I, N) EI2 cells cultured in Activin A, hepatocyte induction medium and then hepatocyte maturation medium (Mature HLC); and (E, J, O) primary human hepatocytes $(\mathrm{PH})$.

constrained by the lack of donor livers for both transplantation and research. Livers that are deemed unsuitable for transplantation are used as the sources for isolated primary hepatocytes for in vitro drug development and toxicology studies. This results in using cells that may have different capacities with regards to their biological functions. ${ }^{1,2}$ Because of these limitations other methods have been developed to attempt to generate cells with the functional characteristics of welldifferentiated hepatocytes and the proliferative capacity to support large-scale production. ${ }^{28-31}$

This study reports the development of a methodology to differentiate the E12 MLPC cell line, immortalized by the insertion of hTERT gene, into cells that express morphology, protein marker, RNA expression and urea production associated with mature hepatocytes. After differentiation, the resultant hepatocyte-like cells retain the immortality and proliferative capacity of the undifferentiated E12 cells.

Transfection with the TERT gene has been shown to functionally immortalize primitive cells like fetal liver cells or bone marrow-derived MSC without affecting their differentiation capacity. In contrast, terminally differentiated cells transfected with TERT lost their proliferative capacity or their biological function with age. ${ }^{32-34}$ Insertion of the TERT gene into the appropriately immature/progenitor/stem cell type could result in an immortalized cell type that still retains the differentiating potential of the initial cell.

Differentiation protocols described in earlier studies with $\mathrm{MSC}^{4-10}$ did not result in functional, fully mature hepatocytelike cells when applied to MLPC. We found that an initial commitment to definitive endoderm mediated by activin A was a necessary first step in differentiation. The second step to a committed hepatocyte precursor required the addition of Stem cell factor, BMP-4 and IL- $1 \beta$ in addition to the factors described in the previously reported studies. The final differentiation to mature hepatocyte-like cells required the addition of DMSO and retinoic acid.

Observations of functional opposite sex liver and pancreas cells in the recipients of cross-sex bone marrow or cord blood transplants have suggested the presence of cells 


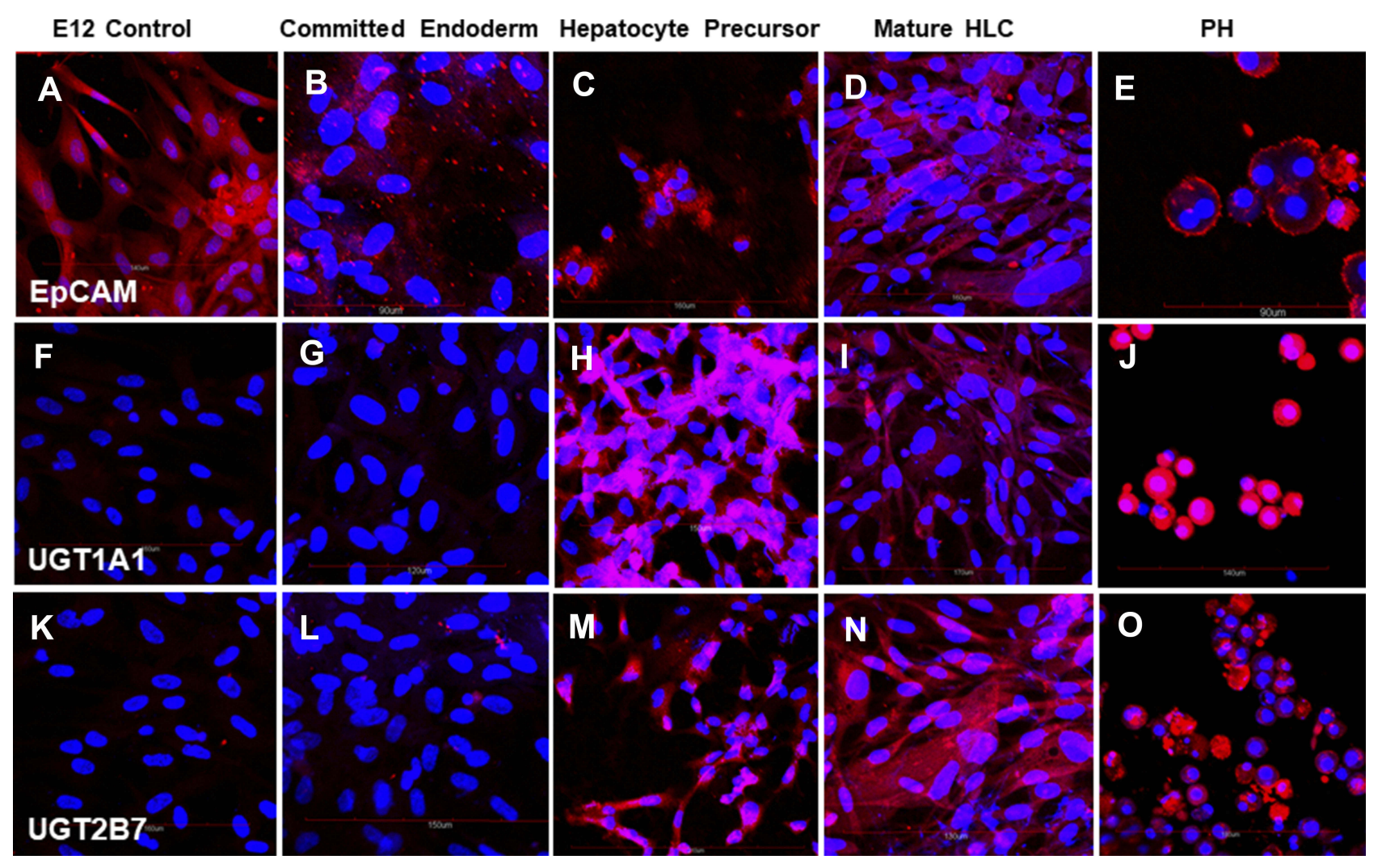

Figure 7 Cells stained with (A-E) EpCAM-specific antibody; (F-J) UGTIAI-specific antibody and (K-O) UGT2B7-specific antibody. All cells were counterstained with DAPI to visualize nuclei (blue). Cells positive for EpCAM, UGTIAI and UGT2B7 stained red. (A, F, K) Undifferentiated control EI2 MLPC; (B, G, L) EI2 MLPC cultured in Activin A medium (Committed endoderm); (C, H, M) EI2 cells cultured in Activin A medium and then hepatocyte induction medium (Hepatocyte precursor); (D, I, N) EI2 cells cultured in Activin A, hepatocyte induction medium and then hepatocyte maturation medium (Mature HLC); and (E, J, O) primary human hepatocytes (PH).

within the transplant that could act as precursors to the final observed cells in the organs of the recipients. ${ }^{35-46}$ Based on those and similar reports, two different possible mechanisms were suggested to explain the occurrence of donor-derived mature cells in the organs of the stem cell recipients: transdifferentiation or cell fusion. A number of studies were designed to answer this question. ${ }^{34,38}$ In a study where human MSC were transplanted directly into rat livers, Sato et al reported that the albuminproducing donor-derived cells in the liver were not the result of cell fusion, but rather due to transdifferentiation of the MSC to hepatocytes. ${ }^{38}$ The estimated success rate of implantation was less than $1 \%$ of the injected cells (possibly reflecting the rarity of these cells within the MSC population). Other studies have also reported transdifferentiation as the mechanism for maturation to hepatocytes. ${ }^{38,41-43}$ Conversely, reports have suggested cell fusion as the mechanism for the appearance of functional opposite-sex donor cells in the liver. ${ }^{44-46}$ Mechanisms for this putative in vivo fusion have yet to elucidated. In a parallel study using E12 TERT cells, a method for the in vitro fusion of the E12 cells with PH resulted in cells with mature hepatocyte characteristics that are functionally immortal. That study is the subject of a separate report.

This study confirms that transdifferentiation could be a potential mechanism for cord blood-derived cells to become functional liver cells. Alternatively, the fusion experiments suggest that fusion could also be a viable mechanism for the appearance of donor cells in the organs of cord blood recipients.

The study reports the development of a methodology with a specific unique cell, the immortalized MLPC cell line E12 that is capable of long-term survival in culture and the ability to be expanded to industrial scale quantities while conserving their hepatocyte-like characteristics. These cells could provide a stable repeatable cell standard for the study of liver function, toxicology testing, and a tool for the development of new therapies for liver disease. These cells could also help develop the methods 


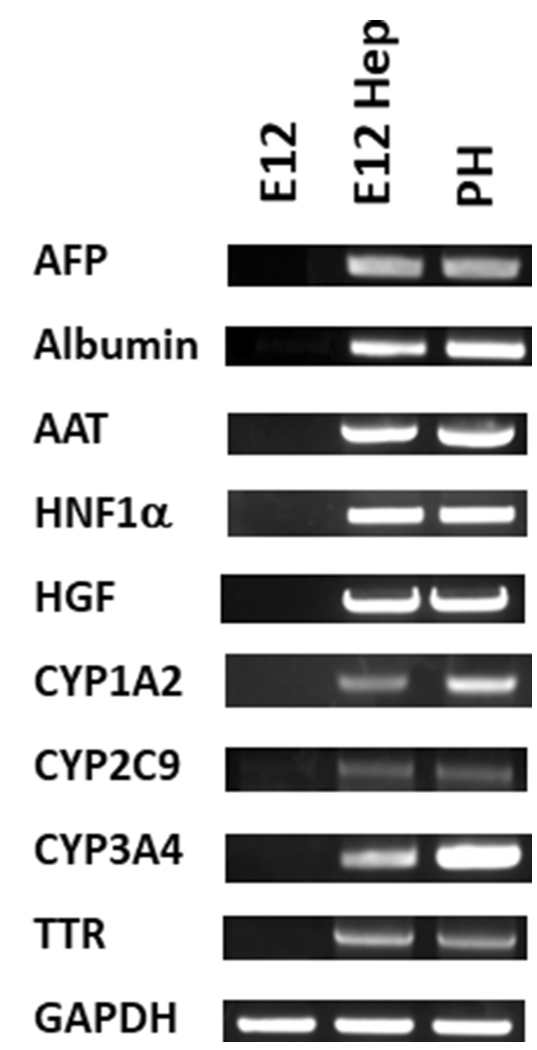

Figure 8 PCR analysis of the EI2 MLPC clonal cell line; hepatocyte-differentiated EI2 MLPC; and $\mathrm{HClO}-3$ primary hepatocytes $(\mathrm{PH})$ for liver-specific mRNA markers.

needed to develop artificial liver support systems as a possible bridge to transplant. ${ }^{26,27}$

\section{Acknowledgments}

We thank Dr. Noriyuki Kashara, Department of Medicine, UCLA, Los Angeles, CA for contributing the hTERT expression plasmid; and Dr. Eve Kelland, Department of Neurology, Keck School of Medicine, USC, Los Angeles, CA for transfection of MLPC cells with the hTERT gene. This work was supported by funds from BioE, LLC (DPC and $\mathrm{JHH}$ ), in addition to a seed grant provided by the Institute for Engineering in Medicine from the University of Minnesota (RNA and CJS).

\section{Author Contributions}

Daniel P. Collins: concept, development of cell culture medium, method of differentiation, design of experiments and tissue culture methods, culture and expansion of cell lines, confocal microscopy, collection and analysis of data, manuscript writing, final approval of manuscript; Joel H. Hapke: experimental design, development of assays and data collection for urea production, analysis of data, manuscript writing, manuscript editing and final approval of manuscript; Rajagopal N. Aravalli: RT-PCR analysis, manuscript writing, collection and analysis of data, final approval of manuscript; Clifford J. Steer: concept of study, experimental design, manuscript editing, and final approval.

\section{Disclosure}

Dr Daniel P Collins is an employee CMDG, LLC, which is under contract to pursue this research funded by BioE, LLC, during the conduct of the study. In addition, Dr Daniel P Collins has a US Patent 7,670,596; Multi-lineage progenitor cells issued, a US Patent 7,622,108; Multi-lineage progenitor cells issued, a US Patent 7,727,763; Differentiation of multi-lineage progenitor cells to respiratory epithelial cells issued, a patent Composition for an in vitro culture medium to maintain and expand stem cell-derived hepatocyte-like cells pending. The authors report no other conflicts of interest in this work.

\section{References}

1. Katsura N, Ikai I, Mitaka T, et al. Long-term culture of primary human hepatocytes with preservation of proliferative capacity and differentiated functions. J Surg Res. 2002;1(1):115-123. doi:10.1006/ jsre.2002.6446

2. Chen HL, Wu HL, Fon CC, Chen PJ, Lai MY, Chen DS. Long-term culture of hepatocytes from human adults. J Biomed Sci. 1998;6 (6):435-440. doi:10.1007/BF02255932

3. Chen Z, Kuang Q, Lao XJ, Yang J, Huang W, Zhou D. Differentiation of UC-MSC's into hepatocyte-like cells in partially hepatectomized model rats. Exp Ther Med. 2016;12(3):1775-1779. doi:10.3892/ etm.2016.3543

4. Lee HJ, Jung J, Cho KJ, Lee CK, Hwang SG, Kim GJ. Comparison of in vitro hepatogenic differentiation potential between various placenta-derived stem cells and other adult stem cells as an alternative source of functional hepatocytes. Differentiation. 2012;84(3):223-231. doi:10.1016/j.diff.2012.05.007

5. Esmaeli S, Allameh A, Soleimani M, Rahbarizadeh F, FrouzandehMoghadam M. The role of albumin and pPAR- $\alpha$ in differentiationdependent change of fatty acid profile during differentiation of mesenchymal stem cells to hepatocyte-like cells. Cell Biochem Funct. 2014;32(5):410-419. doi:10.1002/cbf.3031

6. Su Z, Li P, Wu B, et al. PHBVHHx scaffolds loaded with umbilical cord-derived mesenchymal stem cells or hepatocyte-like cells differentiated from these cells for liver tissue engineering. Mater Sci Eng C Mater Biol Appl. 2014;45:374-382. doi:10.1016/j.msec.2014. 09.022

7. Zhou R, Li Z, He C, et al. Human umbilical cord mesenchymal stem cells and derived hepatocyte-like cells exhibit similar therapeutic effects on an acute liver failure mouse model. PLoS One. 2014;9(8): e104392. doi:10.1371/journal.pone.0104392

8. Chitrangi S, Nair P, Kanna A. Three-dimensional polymer scaffolds for enhanced differentiation of human mesenchymal stem cells to hepatocyte-like cells: a comparative study. J Tissue Eng Regen Med. 2017;11(8):2359-2372. doi:10.1002/term.2136

9. Zhang YN, Lie PC, Wei X. Differentiation of mesenchymal stromal cells derived from umbilical cord Warton's jelly into hepatocyte-like cells. Cytotherapy. 2009;11(5):548-558. doi:10.1080/14653240903 051533 
10. Liang XJ, Chen XJ, Yang DH, Huang SM, Sun GD, Chen YP. Differentiation of human umbilical cord mesenchymal stem cells into hepatocyte-like cells by hTERT gene transfection in vitro. Cell Biol Int. 2012;36(2):215-221. doi:10.1042/CBI20110350

11. van de Ven C, Collins D, Bradley MB, Morris E, Cairo MS. The potential of umbilical cord blood multipotent stem cells for non-hematopoietic tissue and cell regeneration. Exp Hematol. 2007;35(12):1753-1765. doi:10.1016/j.exphem.2007.08.017

12. Collins DP. Multi-lineage progenitor cells (MLPC) an umbilical cord blood-derived multi-potent stem cell that arises from an adherent CD45+/CD34+. Biol Blood Marrow Transplant. 2006;12(11):1227. doi:10.1016/j.bbmt.2006.08.028

13. Collins DP. Multi-lineage progenitor cells (MLPC) an umbilical cord blood-derived multi-potent stem cell that arises from an adherent CD45+/CD34+/CD9+ subset. Stem Cells World Conference; 2007.

14. Burger MJ, Adams SD, Tigges BM, et al. Differentiation of umbilical cord blood-derived multi-lineage progenitor cells into respiratory epithelial cells. Cytotherapy. 2006;8(5):480-487. doi:10.1080/ 14653240600941549

15. Cadet P, Mantione KJ, Zhu W, Kream RM, Sheehan M, Stefano GB. A functionally coupled $\mu 3$-like opiate receptor/nitric oxide regulatory pathway in human multi-lineage progenitor cells. $J$ Immunol. 2007;179(9):5839-5844. doi:10.4049/jimmunol.179.9.5839

16. Stefano GB, Kream RM, Mantione KJ, et al. Endogenous morphine/ nitric oxide-coupled regulation of cellular physiology and gene expression: implications for cancer biology. Semin Cancer Biol. 2008;18(3):199-210. doi:10.1016/j.semcancer.2007.12.003

17. Collins DP, Sprague SL, Tigges BM. Multi-lineage progenitor cells. US Patent 7,670,596. 2010.

18. Collins DP, Sprague SL, Tigges BM. Multi-lineage progenitor cells. US Patent 7,622,108. 2009.

19. McKenna DH Jr., Tigges BM, Berger MJ. Differentiation of multilineage progenitor cells to respiratory epithelial cells. US Patent 7,727,763. 2010

20. Chen ML, Lee KD, Huang HC, et al. HNF- $4 \alpha$ determines hepatic differentiation of human mesenchymal stem cells from bone marrow. World J Gastroenterol. 2010;16(40):5092-5103. doi:10.3748/wjg. v16.i40.5092

21. Deguchi S, Yamashita T, Igai K, et al. Modeling of hepatic drug metabolism and responses in CYP2C19 poor metabolizer using genetically manipulated human iPS cells. Drug Metab Dispos. 2019;47(6):632-638. doi:10.1124/dmd.119.086322

22. Okamoto R, Takayama K, Akita N, et al. Human iPS cell-based liver-like tissue engineering at extrahepatic sites in mice as a new cell therapy for hemophilia B. Cell Transplant. 2018;27(2):299-309. doi:10.1177/0963689717751734

23. Hay DC, Zhao D, Fletcher J, et al. Efficient differentiation of hepatocytes from human embryonic stem cells exhibiting markers recapitulating liver development in vivo. Stem Cells. 2008;26(4):894-902. doi:10.1634/stemcells.2007-0718

24. Sakai K, Takeda M, Okamoto I, Nakagawa K, Nishio K. Multiple regulatory mechanisms of hepatocyte growth factor expression in malignant cells with a short poly(dA) sequence in the HGF gene promoter. Oncol Lett. 2015;9(1):405-410. doi:10.3892/ol.2014.2702

25. Mowbray C, Howard A, Hirst BH. Quantitative PCR in the assessment of novel hepatic cell models. Eur Pharm Rev. 2015;20:8-14.

26. Sen S, Williams R. New liver support devices in acute liver failure: a critical evaluation. Sem Liver Dis. 2003;23:283-294.

27. Garcia Martinez JJ, Bendjelid K. Artificial liver support systems: what is new over the last decade? Ann Intensive Care. 2018;8 (1):109. doi:10.1186/s13613-018-0453-z

28. Aravalli RN, Cressman EN, Steer CJ. Hepatic differentiation of porcine induced pluripotent stem cells in vitro. Vet J. 2012;194 (3):369-374. doi:10.1016/j.tvj1.2012.05.013
29. Agarwal S, Holton KL, Lanza R. Efficient differentiation of functional hepatocytes from human embryonic stem cells. Stem Cells. 2008;26(5):1117-1127. doi:10.1634/stemcells.2007-1102

30. Cai J, Zhao Y, Liu Y, et al. Directed differentiation of human embryonic stem cells into functional hepatic cells. Hepatology. 2007;45(5):1229-1239. doi:10.1002/hep.21582

31. Duan Y, Catana A, Meng Y, et al. Differentiation and enrichment of hepatocyte-like cells from human embryonic stem cells in vitro and in vivo. Stem Cells. 2007;25(12):3058-3068. doi:10.1634/stemcells.2007-0291

32. Dahlke MH, Popp FC, Larsen S, Schlitt HJ, Rasko JEJ. Stem cell therapy of the liver-fusion or fiction. Liver Transpl. 2004;10 (4):471-479. doi:10.1002/lt.20121

33. Deurholt T, van Til NP, Chhatta AA, et al. Novel immortalized human fetal cell line, cBALIII, has the potential to differentiate into functional hepatocytes. BMC Biotechnol. 2009;9(1):89-104. doi:10.1186/1472-6750-9-89

34. Wege H, Le HT, Chui MS, et al. Telomerase reconstitution immortalizes human fetal hepatocytes without disrupting their differentiation potential. Gastroenterology. 2003;2(2):432-444. doi:10.1053/ gast.2003.50064

35. Abdullah BM, Haack-Sorensen M, Burns JS, et al. Maintenance of differentiation potential of human bone marrow mesenchymal stem cells immortalized by human telomerase reverse transcriptase gene despite extensive proliferation. Biochem Biophys Res Commun. 2005;326(3):527-538. doi:10.1016/j.bbrc.2004.11.059

36. Petersen BE, Bowen WC, Patrene KD, et al. Bone marrow as a potential source of hepatic oval cells. Science. 1999;284 (5417):1168-1170. doi:10.1126/science.284.5417.1168

37. Huang CJ, Butler AE, Moran A, et al. A low frequency of pancreatic islet insulin-expressing cells derived from cord blood stem cell allografts in humans. Diabetologia. 2011;54(5):1066-1074. doi:10.1007/ s00125-011-2071-2

38. Sato Y, Araki H, Kato J, et al. Human mesenchymal stem cells xenografted directly into rat liver are differentiated into human hepatocytes without fusion. Blood. 2006;106(2):756-763. doi:10.1182/ blood-2005-02-0572

39. Wang X, Ge S, McNamara G, Hao QI, Crooks GM, Nolta JA. Albumin-expressing hepatocyte-like cells develop in the livers of immune-deficient mice that received transplants of highly purified human hematopoietic stem cells. Blood. 2003;101(10):4201-4208. doi:10.1182/blood-2002-05-1338

40. Ishikawa F, Drake CJ, Yang S, et al. Transplanted human cord blood cells give rise to hepatocytes in engrafted mice. Ann NY Acad Sci. 2003;966(1):174-185. doi:10.1111/j.1749-6632.2003.tb03245.x

41. Newsome PN, Johannessen I, Boyle S, et al. Human cord blood-derived cells can differentiate into hepatocytes in the mouse liver with no evidence of cellular fusion. Gastroenterology. 2003;124 (7):1891-1900. doi:10.1016/S0016-5085(03)00401-3

42. Lagasse E, Connors H, Al-Dhalimy M, et al. Purified hematopoietic stem cells can differentiate into hepatocytes in vivo. Nat Med. 2000;6 (11):1229-1234. doi:10.1038/81326

43. Wang X, Willenbring H, Akkari Y, et al. Cell fusion is the principal source of bone-marrow-derived hepatocytes. Nature. 2003;422 (6934):897-901. doi:10.1038/nature01531

44. Medvinsky A, Smith A. Stem cells: fusion brings down barriers. Nature. 2003;422(6934):823-825. doi:10.1038/422823a

45. Wagers AJ, Sherwood RJ, Christensen JL, Weissman IL. Little evidence for developmental plasticity of adult hematopoietic stem cells. Science. 2002;297(5590):2256-2259. doi:10.1126/science.1074807

46. Theise ND, Krause DS, Sharkis S. Comment on little evidence for developmental plasticity of adult hematopoietic stem cells. Science. 2003;299(5611):1317. doi:10.1126/science. 1078412 


\section{Publish your work in this journal}

Hepatic Medicine: Evidence and Research is an international, peerreviewed, open access journal covering all aspects of adult and pediatric hepatology in the clinic and laboratory including the following topics: Pathology, pathophysiology of hepatic disease; Investigation and treatment of hepatic disease; Pharmacology of drugs used for the treatment of hepatic disease. Issues of patient safety and quality of care will also be considered. The manuscript management system is completely online and includes a very quick and fair peer-review system, which is all easy to use. Visit http://www.dovepress.com/ testimonials.php to read real quotes from published authors.

Submit your manuscript here: https:/www.dovepress.com/hepatic-medicine-evidence-and-research-journal 